This item was submitted to Loughborough's Research Repository by the author.

Items in Figshare are protected by copyright, with all rights reserved, unless otherwise indicated.

\title{
A fully coupled, 6 degree-of-freedom, aerodynamic and vehicle handling crosswind simulation using the DrivAer model
}

PLEASE CITE THE PUBLISHED VERSION

http://dx.doi.org/10.4271/2016-01-1601

PUBLISHER

(C) SAE International

VERSION

VoR (Version of Record)

\section{PUBLISHER STATEMENT}

This work is made available according to the conditions of the Creative Commons Attribution-NonCommercialNoDerivatives 4.0 International (CC BY-NC-ND 4.0) licence. Full details of this licence are available at: https://creativecommons.org/licenses/by-nc-nd/4.0/

\section{LICENCE}

CC BY-NC-ND 4.0

\section{REPOSITORY RECORD}

Forbes, David, Gary Page, Martin Passmore, and Adrian P. Gaylard. 2016. "A Fully Coupled, 6 Degree-offreedom, Aerodynamic and Vehicle Handling Crosswind Simulation Using the Drivaer Model”. Loughborough University. https://hdl.handle.net/2134/21523. 


\title{
A Fully Coupled, 6 Degree-of-Freedom, Aerodynamic and Vehicle Handling Crosswind Simulation using the DrivAer Model
}

\author{
David C. Forbes, Gary J. Page, and Martin A. Passmore \\ Loughborough University \\ Adrian P. Gaylard \\ Jaguar Land Rover
}

\begin{abstract}
In a real-world environment, a vehicle on the road is subjected to a range of flow yaw angles, the most severe of which can impact handling and stability. A fully coupled, six degrees-of-freedom CFD and vehicle handling simulation has modelled the complete closed loop system. Varying flow yaw angles are introduced via time dependent boundary conditions and aerodynamic loads predicted, whilst a handling model running simultaneously calculates the resulting vehicle response. Updates to the vehicle position and orientation within the CFD simulation are achieved using the overset grid method. Using this approach, a crosswind simulation that follows the parameters of ISO 12021:2010 (Sensitivity to lateral wind - Open-loop test method using wind generator input), was performed using the fastback variant of the DrivAer model. Fully coupled aerodynamic and vehicle response was compared to that obtained using the simplified quasi-steady and unsteady, one way coupled method. Between the quasi-steady and unsteady simulations, an overshoot in aerodynamic yaw moment for the latter resulted in a larger lateral deviation of approximately $8 \%$. However, the differences in responses between the transient, one-way and fully coupled methods were small for this particular geometry. It is expected that by increasing gust length, differences will appear, as the vehicle is exposed to the larger flow yaw angle for a longer period.
\end{abstract}

CITATION: Forbes, D., Page, G., Passmore, M., and Gaylard, A., "A Fully Coupled, 6 Degree-of-Freedom, Aerodynamic and Vehicle Handling Crosswind Simulation using the DrivAer Model," SAE Int. J. Passeng. Cars - Mech. Syst. 9(2):2016, doi:10.4271/2016-01-1601.

\section{INTRODUCTION}

In the UK, average annual wind speeds fall in the range of $4-5 \mathrm{~m} / \mathrm{s}$, which at typical vehicle speeds of $100 \mathrm{~km} / \mathrm{h}$ can produce flow yaw angles up to $10^{\circ}[\underline{1}]$. In contrast, maximum mean hourly wind speeds of up to $24 \mathrm{~m} / \mathrm{s}$ over flat, open, central parts of the UK have been recorded, albeit with a probability of occurring once in 50 -year period $[\underline{1}, \underline{2}]$. Whilst data describing instantaneous peak values is rare, values greater than this mean can be expected. Nevertheless, these speeds correspond to a much larger maximum flow yaw angle of approximately $40^{\circ}$. Such high angles and speeds present a safety concern as it will be shown that at these values, the forces acting on the vehicle are large enough to cause a substantial course deviation and in some cases, are large enough for the vehicle to encroach upon adjacent lanes.

This issue will become even more prevalent with the current trend towards lighter, more fuel efficient vehicles, in a bid to meet emissions regulations brought about by the 'Worldwide Harmonized Light Vehicles Test Procedure' (WLTP) []].

It is generally assumed that as any lateral or yaw accelerations are sensed a driver will be able to provide an adequate counter response to a gust to prevent a significant deviation. However, this is not always the case because when the frequency of the gust is combined with the drivers inputs the driver's response can amplify the vehicle's deviation. This is shown by Wagner and Wiedemann [4], within a frequency range of $0.5-2 \mathrm{~Hz}$, to occur as the vehicle motion due to the crosswind and the driver's steering input approach an in-phase state, peaking at a frequency of $1.4 \mathrm{~Hz}$. For frequencies $<0.5 \mathrm{~Hz}$, the driver typically has a positive influence on the vehicle's response, as the gust and loads acting on the vehicle are quasi-steady. Whereas at higher frequencies $>2 \mathrm{~Hz}$, the driver has little to no influence, as the gust has passed before it is felt.

In order to assess the complete vehicle-driver response to such an event, a flow disturbance has to be generated, either naturally or artificially. The aerodynamic response of a vehicle during a crosswind has been investigated using numerous methods. On road vehicle testing $[\underline{5}, \underline{6}, \underline{7}, \underline{8}, \underline{9}]$ is often preferred as it places a representative driver and vehicle in a real-world environment, whilst crosswind generators beside test tracks $[\underline{10}, \underline{11}]$ offer a degree of control over gust parameters.

An International Standard ISO 12021:2010 [13] has been derived in an attempt to standardize such facilities. These guidelines appear to be based on the work of Howell [11] , in which a trifurcated tail pipe attached to the exhaust of a jet engine was used to determine the behavior of a small Sports Utility Vehicle (SUV) when passing 
through a severe crosswind. The experimental setup generated a flow yaw angle of $27.5^{\circ}$ at a vehicle speed of $100 \mathrm{~km} / \mathrm{h}$, with a disturbance frequency of $0.7 \mathrm{~Hz}$. Gyroscopic rate transducers and accelerometers were fitted to measure the chassis moment rates and lateral accelerations respectively, while course deviation was measured with a dye trail. With a fixed steering input, (steering wheel held in a fixed position) the vehicle reached an average lateral deviation of 2 metres, 2 seconds from the point of entering the crosswind. The downside to these tests is the limited flow field data that can be extracted, making it difficult to identify the flow structures responsible for the deviation. In addition, such tests cannot be performed without a prototype vehicle, at which stage, significant financial investment has been placed into the design and modifications can be very costly.

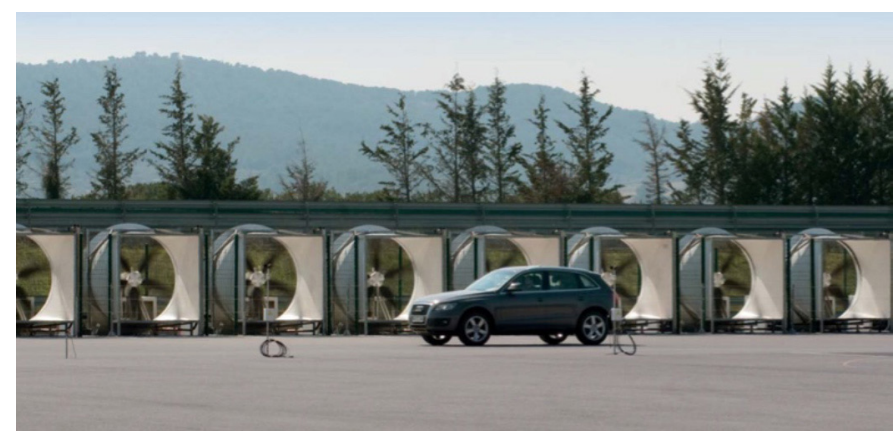

Figure 1. Crosswind Generator Facility at Applus+ IDIADA Proving Ground, Spain [12]

For this reason, full scale and model scale wind tunnel tests are an appealing alternative. The accepted method of testing such events has changed since the early tests of Beauvais [14], who traversed a vehicle across the width of the working section on a purpose built track. In more recent years, dynamically yawed flow has been generated using vertical oscillating airfoils upstream of the test section, as employed by Bearman and Mullarkey [15], Passmore, Richardson and Imam [16], Schroeck et al. [17], Mankowski, Sims-Williams and Dominy [18] and the system at FKFS Stuttgart [19]. Such devices are capable of generating the large length scales representative of the majority of on-road gusts. In addition, it has been shown that active drag-based devices such as the upstream deployable blades at Pininfarina $[\underline{20}, \underline{21}]$ can be used to generate dynamically yawing flow by controlling the relative phasing of the opening and closing of the blades [22].

Although these upstream devices make it possible to investigate a meaningful region of the aerodynamic coefficients frequency spectra, they are unable to reach the large flow yaw angles representative of an extreme gust that will expose any safety concerns. Ryan and Dominy [23] introduced an alternative arrangement, in which the model is kept stationary in a conventional wind tunnel and a crosswind jet scans along the model. This was achieved with a secondary tunnel placed at a $30^{\circ}$ angle to the axis of the main working section. The model is gradually exposed to the secondary flow through a moving belt with variable aperture or in an updated configuration, an actuated shutter mechanism [24, 25]. Although this method allows for large flow yaw angles, the opening and closing mechanism is unable to produce a smooth gust profile with significant under and overshoots in flow yaw angle occurring.
An appealing alternative in the study of crosswind aerodynamics uses computational fluid dynamics (CFD). This type of simulation removes many of the restrictions imposed by physical testing, with parameters such as flow yaw angle and gust length simply given as boundary values. Many studies have reproduced realistic on road turbulence levels using CFD such as Gaylard et al. [26], D'Hooge et al. [27], and Theissen [료], with emphasis on accurate wind averaged drag values. These simulations limit flow yaw angles to a range of $\pm 5^{\circ}$ and thus can be classed separately to those of isolated extreme gusts which present a safety issue, however such conditions are important to manufacturers because they contribute to quality and refinement issues with respect to noise and ride comfort.

Simulating the impact of gusts on a vehicle's response requires a coupling between aerodynamics and vehicle handling. The coupling method can vary in complexity, and in practice, choice is normally driven by computational resources. However, it is necessary to quantify the differences between the methods and fully understand the shortcomings and advantages of one approach over another, before the choice of a particular method can be justified. Over the last ten years, research in this area has been led by Tsubokura, Nakashima et al. with the emphasis on heavy duty trucks $[\underline{29}, \underline{30}, \underline{31}, \underline{32}, \underline{33}, \underline{34}$, 35]. Due to their large lateral area and extreme weight variations, this class of vehicle are highly susceptible to crosswinds. The coupling methods that have been identified are as follows.

1. Quasi-Steady Static Coupling - Lookup table of quasi - steady aerodynamic loads over a range of yaw angles. Used to generate approximate aerodynamic response during the gust for input into the handling model.

2. Unsteady Static Coupling - A transient history of aerodynamic loads during a convected crosswind event over a static model (equivalent to the shutter device of Dominy and Ryan) temporal loads used as handling model inputs.

3. Unsteady Dynamic Coupling - A closed-loop system with CFD simulation and handling model running simultaneously. Realtime position of the vehicle used in CFD, calculated based on preceding aerodynamic loads. Closest representation of the on road system.

The simplest approach is a quasi-steady static coupling. This method consists of a set of steady state solutions at different flow yaw angles forming, through interpolation methods, an aerodynamic input for a handling model. In its simplest form this involves two solutions: one at zero yaw and one at the gust's maximum yaw angle, yielding a step input. However, Nakashima et al. [31] show that for a severe crosswind $\left(>30^{\circ}\right)$, the quasi-steady approach is unable to capture the overshoot and undershoot of the aerodynamic yawing moment and drag force present in the transient, unsteady static coupling method. This is attributed to a difference in the yaw angle at the front and rear of the vehicle and delayed reaction of the flow passing over the vehicle as it enters and exits the crosswind [32]. This effect will be more pronounced for the long trucks used in their study, but the principle still applies to smaller road vehicles. 


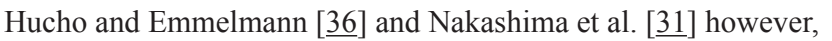
show that where long, shallow gust gradients in relation to the vehicle length and small flow yaw angles $<10^{\circ}$ exist, a quasi-steady behavior of the transient yawing moment occurs, due to a smaller difference in yaw angle at the front and rear of the vehicle, hence justifying the use of this coupling method. The vehicle dynamic response of Nakashima et al. [31] showed a similar relationship to the aerodynamic response. At small flow yaw angles $<10^{\circ}$, the quasi-steady coupling method captured the lateral deviation and yaw angle vehicle responses of the unsteady-static method to within an acceptable range. Increasing the yaw angle of the crosswind $>30^{\circ}$, the differences between the quasi-static and unsteady-static responses were magnified [ $[\underline{31}, \underline{34}]$. As expected, reduced vehicle load (essentially a reduction in the weight) also enhanced the differences between a quasi-static and unsteady-static response, albeit for the large load variations typical of heavy duty trucks. This highlights the importance of reduced vehicle weight on stability. A useful reminder and consideration for the current design trend and subsequent testing procedures. The distinct advantage of the quasi-steady approach is the significant reduction in computational expense when compared to the time taken to obtain a corresponding, fully transient aerodynamic response.

In both the quasi-steady static and unsteady static coupling approaches, the vehicle is fixed in the CFD simulation and the resulting aerodynamics are provided to the handling model as inputs; two separate simulations performed sequentially and the coupling is one-way. It offers the advantage of static CFD geometry, negating the need for computationally expensive dynamic grid methods such as rapid-remeshing, grid deformation and overset (Chimera) grids, but neglects any positional change of the vehicle that results from the aerodynamic loads. Thus any damping or intensifying effects that the vehicle deviation may induce on the flow are not included.

An alternative coupling method, and one which can be considered the most representative of real world on road interactions, is unsteadydynamic. This approach uses one of the aforementioned dynamic meshing models to continually update the vehicle position in the CFD simulation. The positional change is calculated by a handling model running simultaneously using instantaneous aerodynamic loads from the CFD. To date studies that investigate this final approach are limited $[\underline{33}, \underline{35}]$. Such studies use the grid-deformation method based on the Arbitrary Lagrangian-Eulerian (ALE) formulation combined with a moving reference frame approach to include yaw rotation and lateral translation respectively. Thus these simulations are classed as having only two degrees of freedom (2DoF). In the published work comparisons are only made to the quasi-static coupling and display significant variations in both course deviation and the required driver input. However, these studies do not make comparisons between the two unsteady approaches, hence the value of the more computationally expensive unsteady-dynamic coupling method cannot be verified. There is evidence in the predicted loads to suggest that rolling moment and lift force have a sizeable impact on the vehicle response, thus a $6 \mathrm{DoF}$ simulation that includes rotation and translation about all three axes may yield a different response and hence should be investigated.
It is the purpose of this work to quantify the differences between the various coupling methods so that a chosen method can be used to assess crosswind sensitivity much earlier in the development of a production vehicle. In addition, the source of any differences in response will be identified in the flow structures. This will demonstrate the practicality of using such a simulation for shape modifications or testing of stability devices before prototype manufacture. The chosen vehicle for this study is a full-scale representation of the DrivAer model's fastback variant [37]. This variant was chosen over the notchback and estate back options as it has been shown to generate a larger aerodynamic yawing moment when subjected to crosswinds due to a reduction of rear side force in accordance with rear-end area and thus deemed more sensitive to gusts [38]. The specific configuration of the model includes a smooth underbody, closed body with mirrors, fixed non-rotating wheels with smooth tread-less tyres.

\section{CROSSWIND PROFILE}

The simulated crosswind event follows the conditions set out in the International Standard ISO 12021:2010 [13], in an attempt to ease any future experimental validation. This standard calls for a crosswind velocity of $20 \mathrm{~m} / \mathrm{s}$ and vehicle speed of $27.8 \mathrm{~m} / \mathrm{s}(100 \mathrm{~km} / \mathrm{h})$ thus generating a flow yaw angle of approximately $36^{\circ}$ (a severe gust). At its maximum, this arrangement generates a resultant velocity of $34 \mathrm{~m} / \mathrm{s}$ and Reynolds number of approximately 10 million (based on vehicle length). For a two second period after the vehicle enters the crosswind, there is no driver response and the steering wheel is held fixed in accordance with the standard. This condition removes the variability of a driver's response, advantageous for repeatability and simulation, but also gives a good indication of vehicle deviation when a driver is tired or distracted. A gust length of approximately $18.5 \mathrm{~m}$, (four car lengths, $4 \mathbf{L}$ ) is above the minimum length prescribed by the standard, and at this vehicle speed, corresponds to an event duration of 0.66 seconds for a fixed point on the vehicle. This time period corresponds to a disturbance frequency of $1.5 \mathrm{~Hz}$. It has been shown that around this frequency, the driver's and vehicle reactions are in phase, thus intensifying the vehicle reactions to their full extent [4]].

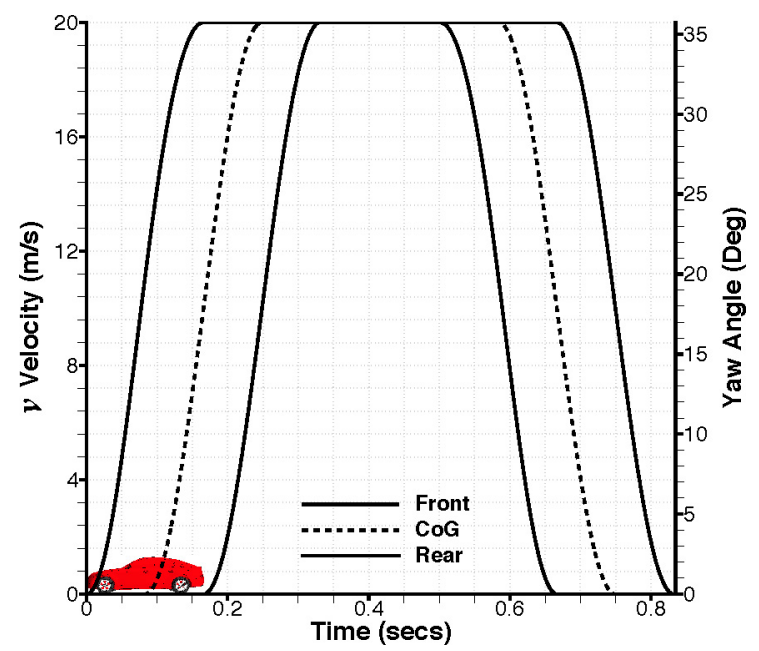

Figure 2. Crosswind Profile (Vehicle speed $u=100 \mathrm{~km} / \mathrm{h}$, disturbance frequency $1.5 \mathrm{~Hz})$. 
The crosswind has a trapezoidal profile with maximum velocity of $20 \mathrm{~m} / \mathrm{s}$ and thus assumes the crosswind facility generates a constant band of flow. The two mixing layers either side of the generator are modelled by cosine functions based on the experimentally validated results of Hucho and Emmelman [36], with lengths of one vehicle length each. Thus the vehicle is only fully immersed in the crosswind for distance equal to one vehicle length. Although shorter in duration, the overall profile is similar to that used by Favre [39] and as shown by Wojciak et al. [누], the shape is representative of approximately a third of all on-road gusts (although on-road tests were only conducted in a single location over several days).

\section{CFD BOUNDARY CONDITIONS}

To impose the crosswind profile on the flow, time dependent boundary conditions are required. The method used by Demuth and Buck [41], uses periodic boundaries as compared to the more traditional method of multiple inlets and outlet used by Tsubokura, Nakashima et al. [29, $\underline{30}, \underline{31}, \underline{32}, \underline{33}, \underline{34}, \underline{35}]$ and Favre [39]. Advantages of this boundary type are their unreflective nature and the single time-dependent velocity function requirement at the main inlet to convect the profile downstream. When using this method, it is important that disturbances re-entering the domain do not influence the flow over the vehicle, but this is rare at typical vehicle speeds and can always be resolved by widening the domain. This method uses a reference frame fixed on the vehicle and thus the $\boldsymbol{u}$ velocity component of the flow represents the reciprocal of the vehicle velocity, as is standard practice from a wind tunnel point of view. However, an issue will arise during the unsteady-dynamic simulation when the vehicle yaws in response to the crosswind: unless the $\boldsymbol{u}$ velocity component of the flow yaws at the same rate as the vehicle it will no longer represent the reciprocal of the vehicle velocity. It is not possible to impart this additional yaw angle to the flow, since any perturbation has to be defined at the inlet in advance, at which point the vehicle yaw angle is unknown.

The overset grid method provides a way around this difficulty by switching the reference frame and allowing a sub-mesh containing the vehicle to move at a constant forward speed through a fluid domain of still air, and static band of crossflow. Thus as the vehicle yaws in response to the crosswind, it will remain at a constant forward speed in its own reference frame. The actual boundaries for this method are similar to that used by Tsubokura, Nakashima et al. $[\underline{29}, \underline{30}, \underline{31}, \underline{32}, \underline{33}, \underline{34}, \underline{35}]$ and Favre [어] with two inlets and two outlets however there is now no time dependency and the only conditions are the $v$ crosswind velocity profile on the crosswind inlet.

Consequently, the three coupling approaches each use a different set of boundary conditions. The quasi-steady static coupling uses two inlets and two outlets without any time dependency to impinge a constant flow yaw angle on the vehicle, Figure 3 . The unsteady static coupling uses the periodic boundary conditions whilst the unsteady dynamic coupling uses the overset boundary conditions, with two inlets and outlets Figures 4 and $\underline{5}$. All methods use the slip wall condition on the top and bottom boundaries, with fixed, grounded, non-rotating wheels and tyres.

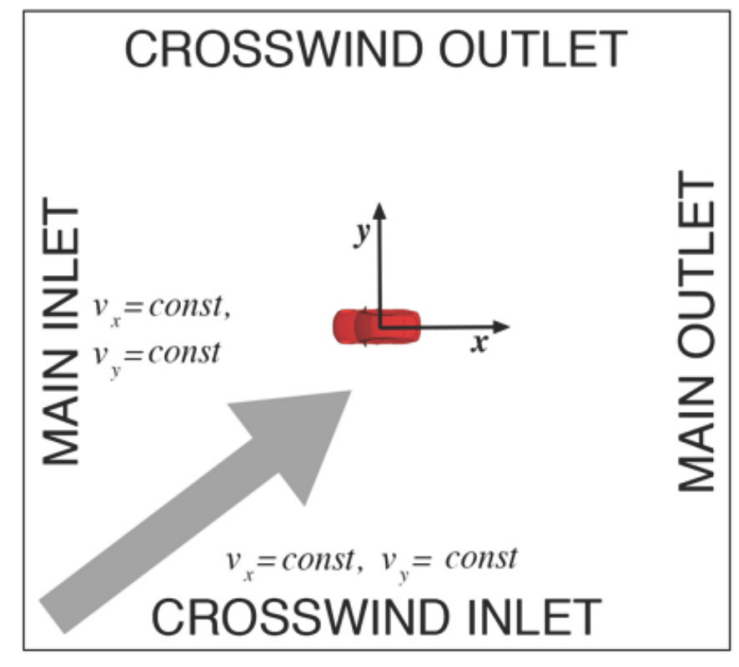

Figure 3. Quasi-Steady Static Boundary Conditions.

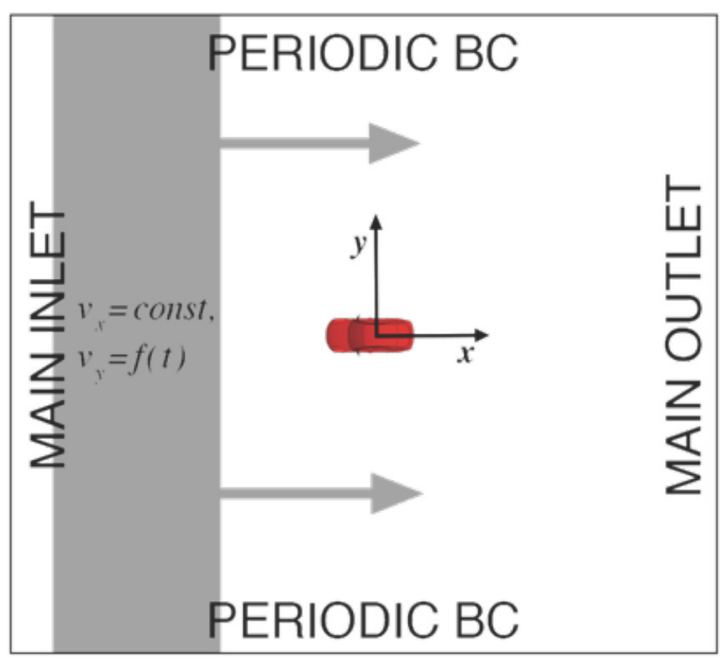

Figure 4. Unsteady Static Boundary Conditions.

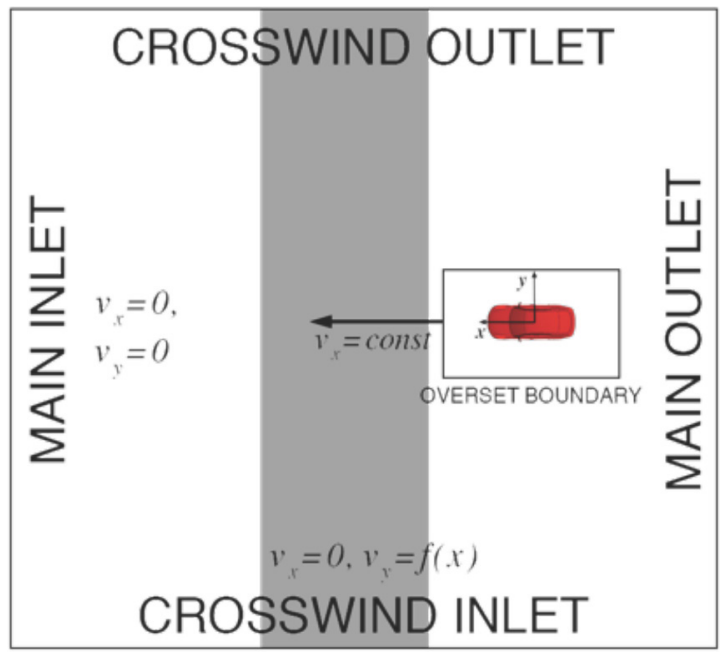

Figure 5. Unsteady Dynamic Boundary Conditions. 


\section{COMPUTATIONAL GRID AND NUMERICAL APPROACH}

For all three cases, the size of the domain $(x=21 \mathbf{L}, \boldsymbol{y}=13 \mathbf{L}, \boldsymbol{z}=2 \mathbf{L})$ and the refinement around the vehicle stays the same. The only variations are the position of the vehicle with its refinement within the domain, and the position of some additional refinement to maintain the crossflow. For the unsteady static case, the vehicle is positioned $27.8 \mathrm{~m}(\sim 6 \mathbf{L})$ from the inlet, corresponding to a one second period for the crosswind to convect downstream before hitting the front of the vehicle. A low-level of refinement is applied to this upstream region, to limit the dissipation of the profile, Figure 6 . This grid is also used for the quasi-steady simulations and contains 16.4 million hexahedral elements.

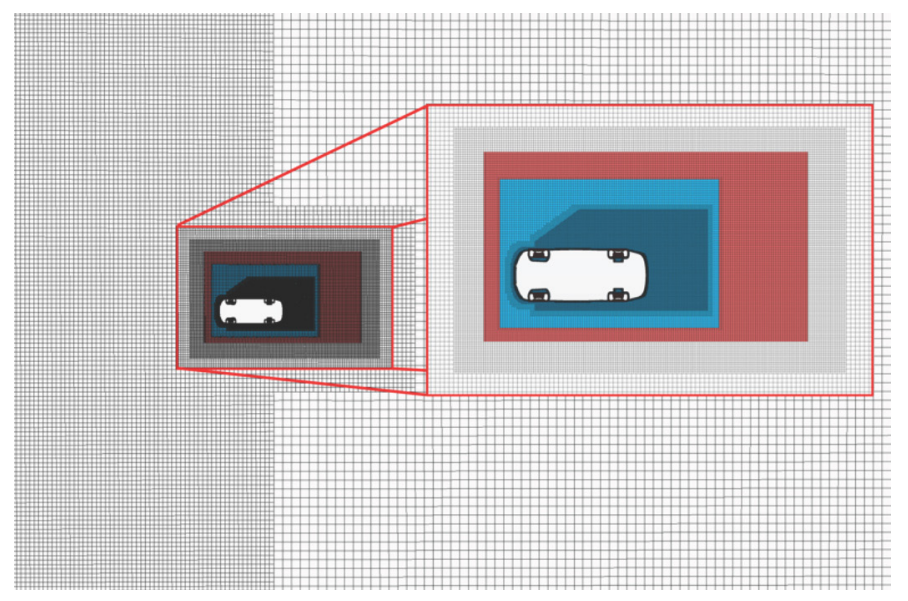

Figure 6. Static Grid, 16.4M Hexahedral Elements.

For the unsteady dynamic case, as the vehicle now moves and the crosswind band is static, the vehicle is positioned at the end of the domain with the crossflow refinement region starting $27.8 \mathrm{~m}(\sim 6 \mathbf{L})$ upstream from the front of the vehicle. This again allows a one second initialization period, before the vehicle reaches the crosswind. In addition, to minimize interpolation errors, refinement along the vehicle's path is needed as a requirement of the overset procedure. Due to the additional refinement, the number of elements increases to 20.3 million, Figure 7.

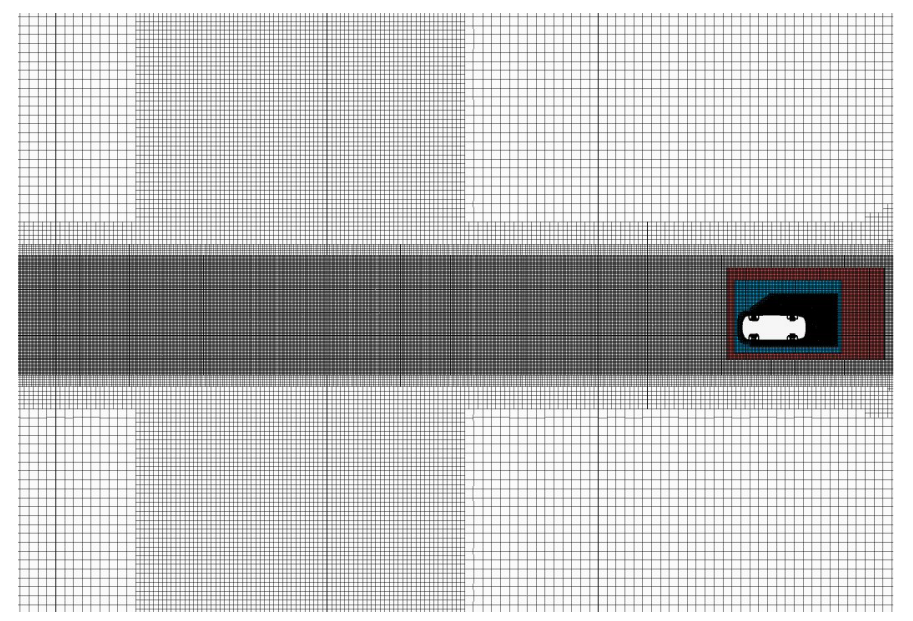

Figure 7. Dynamic Grid, 20.3M Hexahedral Elements.
Figure 8 shows the convergence of the drag and lift coefficient during the one second initialization period. The averages over the final 0.5 seconds of this period are shown in Table 1 and compare well with several experimentally obtained values using the same model configuration and similar fixed wheel test conditions. The variation in the drag coefficient values between the static and dynamic grids can be explained by a variation in the upstream grid refinement and error in the interpolation schemes used by the overset method. Interestingly, the variation in the values happens to coincide with that of the experimental studies. The difference in the lift coefficient values to the single experiment value may result from the experimental setup which featured a mounting strut under the vehicle and small clearances between the flatted tyres and ground not simulated.

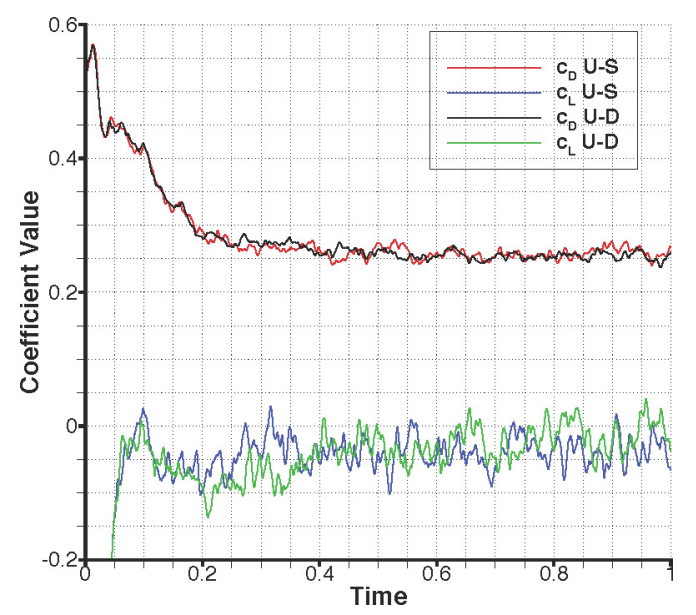

Figure 8. Drag and Lift coefficient convergence during initialization period.

Table 1. Average drag and lift coefficient values of final 0.5 seconds of initialization - Comparison to experimental values.

\begin{tabular}{|l|c|c|}
\hline & $\mathbf{C}_{\mathbf{D}}$ & $\mathbf{C}_{\mathbf{L}}$ \\
\hline Unsteady Static & 0.258 & -0.038 \\
\hline Unsteady Dynamic & 0.254 & -0.022 \\
\hline Wieser et al. [42] & 0.258 & -0.096 \\
\hline Heft et al. [37] & 0.254 & - \\
\hline
\end{tabular}

The refinement around the vehicle is contained within overset boundaries (indicated by the blue and red regions), hence the refinement moves with the vehicle. The smallest element size within this region is $10 \mathrm{~mm}\left(2 \times 10^{-3} \mathbf{L}\right)$, whilst 8 prism layers to a combined wall normal distance of $5 \mathrm{~mm}$ ensure a $\mathrm{y}^{+<20}$ on all vehicle surfaces.

To allow for motion in $6 \mathrm{DoF}$, two overset regions are required. The first contains the wheels and tyres and the second the body, Figure 9. When applying motion to these regions, $\mathrm{x}$ and $\mathrm{y}$ translation along with yaw rotation is applied to both, however, $\mathrm{z}$ heave and roll and pitch rotations are only applied to the body region, thus simulating suspension motions. The complexity of this simulation could be increased by adding overset regions around each wheel to simulate true wheel rotation, steering angles and in extreme case, losing ground contact. Although this will incur added computational cost. 
The overset method is very sensitive to grid size, with significant increases in computational effort based on the number of elements at the overset-background interface. For this reason, it is advantageous to place the interfaces in coarser regions. Consequently, this behavior has a heavy-weighting on the resolution of elements within the grid and overall grid size. The current grids enable practical run times with the available computational resources.
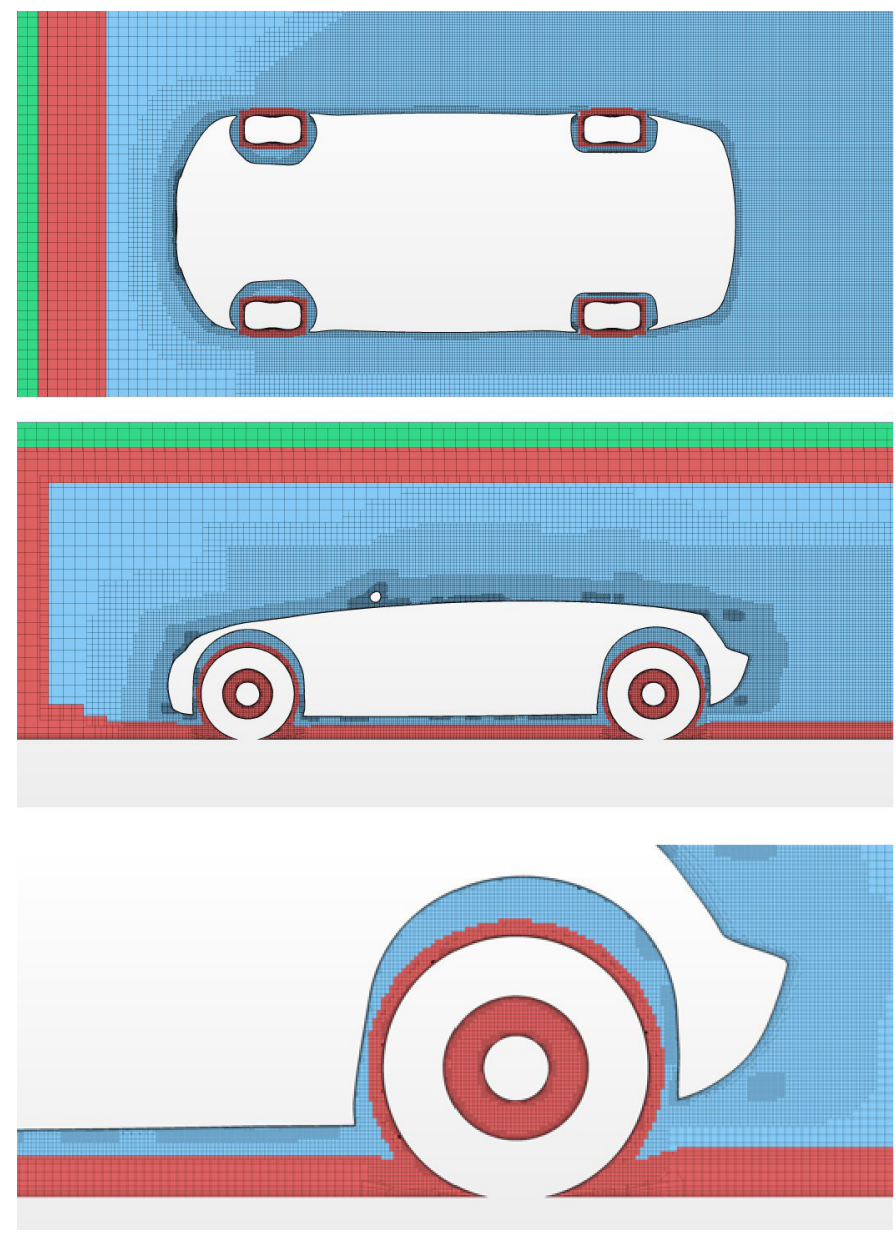

Figure 9. Overset Grids.

A segregated, incompressible, finite volume, semi-implicit, pressure based solver was chosen for all simulations with a hybrid $2^{\text {nd }}$ order upwind/bounded central-differencing convection scheme. Turbulence was modelled with the DDES variant of the Spalart-Allmaras DetachedEddy model, selected due to the coarse grid and complex geometry. Geometry of this type featuring curvature and sharp angles restrict the highly anisotropic grid elements near walls, desirable for RANS selection in this hybrid RANS-LES model. As described by Spalart et al. [43], these ambiguous grids, where the DES limiter is activated within the boundary layer, can lead to modelled-stress depletion, and ultimately unphysical, grid-induced separation. The DDES variant attempts to resolve this by including a dependency on the eddy-viscosity field alongside the grid dependency in the DES length scale calculation, helping to ensure RANS selection for the entire boundary layer, and LES treatment away from the wall, Figure 10.
A second-order temporal scheme limits the numerical dissipation of the crossflow and time-step of $1 \times 10^{-4} \mathrm{~s}$ ensures a Courant number below one within the LES region. Five inner iterations per time-step ensure consistent convergence of the residuals, whilst dynamic repartitioning keeps loads balanced across 320 parallel processors as the grid is updated. All CFD simulations were carried out using CDAdapco's Star-CCM+ v10.04.009 and ran on the HPC-Midlands Facility, UK. The ISO crosswind standard calls for a 2 second period without driver response and hence, with the one second initialization, the unsteady simulations run for a combined total simulated time of 3 seconds.

The total elapsed run times for the unsteady static and unsteady dynamic CFD simulations were 34 and 150 hours respectively. The time taken to obtain a single, one second, (6 car lengths) timeaveraged DES solution at constant yaw angle for the quasi-steady static simulation was 12 hours. Hence, as a minimum of two simulations are required for this method, the total elapsed time was 24 hours. In all cases the time taken for the vehicle handling model was negligible in comparison.

It is understood that the grid and numerical approach are coarse when compared to typical vehicle DES simulations, with grids typically containing upwards of a hundred million elements. These high resolution grids are generally used to obtain highly accurate drag value predictions which is not the objective of this study. The intention of this work is to demonstrate this fully coupled technique. Whilst a highly accurate flow field prediction is desired, at this early stage a coarse grid should still extract the large flow structures which dominate the aerodynamics to a reasonable level of accuracy. It appears that the most similar work of Tsubokura, Nakashima et al. $[\underline{29}, \underline{30}, \underline{31}, \underline{32}, \underline{33}, \underline{34}, \underline{35}]$ adopted a similar strategy with grids containing approximately 20 million elements.

Whilst grids of this size for full-scale vehicle aerodynamics are usually associated with RANS based simulations, DES was chosen based on the results of a previous study comparing solver suitability for typical SUV geometry [44]. More relevant, is the work of Ashton and Revell [45], who compare RANS and DES methods in predicting the flow field over the DrivAer model. Both studies endorse the use of DES due to clear improvements in drag coefficient, pressure distribution and overall flow field predictions over RANS methods. It should be mentioned that both studies use significantly finer grids than that used in the current work.

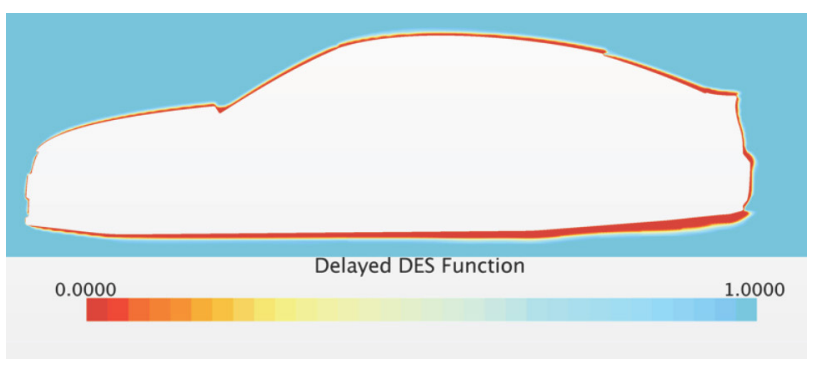

Figure 10. Delayed DES Function $f_{d}\left(f_{d}=0\right.$ RANS treatment, $f_{d}=1$ LES treatment). 


\section{VEHICLE HANDING MODEL}

An implementation of the vehicle handling model described in [46] and assembled in model-based design environment Simulink ${ }^{\circledR}$ integrated within MATLAB ${ }^{\circledR}$ was used. The essential features are as follows. The vehicle is modelled as a rigid body, free to move in six degrees of freedom under the influence of nominal drag and tyre forces found from a combined slip Pacejka formula. The vertical load used in these calculations is computed assuming a linear springdamper suspension system compensated by suspension link forces that act at static roll centres. The model is initialized with values representative of an average family saloon, with dimensions consistent to those of the full-scale DrivAer geometry. The model includes the weight of the driver alone and no passengers or additional load.

\section{CFD-VEHICLE HANDLING COUPLING}

Coupling between Star-CCM+ and MATLAB is achieved using a Level 2 MATLAB S-Function. This function opens up a Unix port on the remote machine through which vehicle positional data is sent in the form of translational and angular velocities. Star-CCM+ links to this port using a collection of Java macros, loading the positional data and returning aerodynamic forces and moments. This system is shown in Figure 11. An advantage of this system is that running both simulations on the same host is not a requirement. For the current simulations, MATLAB runs on the local host, connecting to Star-CCM+ running in parallel on 320 processors of the HPC-Midlands facility.

Due to the differences in timescales between the motions of the fluid and vehicle, the time-step of the handling model is an order of magnitude smaller than that of the CFD simulation. Hence this data exchange only occurs every ten fluid time-steps. This is also the exchange rate for the one-way coupled methods.

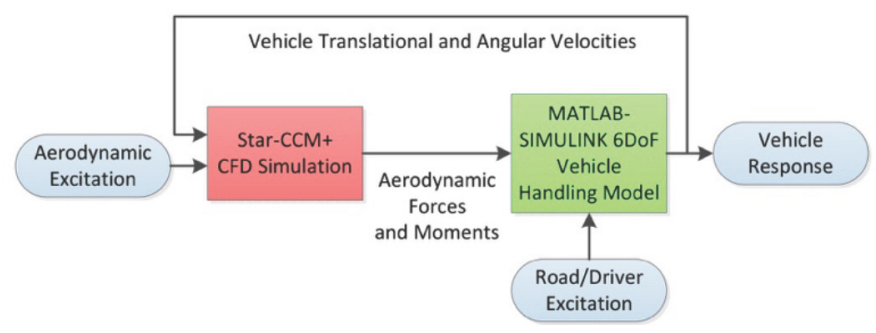

Figure 11. CFD-Vehicle Handling Coupled System.

\section{RESULTS}

\section{Aerodynamic Response}

Before analyzing the effect of coupling, a comparison between the quasi-steady and unsteady aerodynamics is made. All aerodynamic loads adopt the aerodynamic coordinate system SAE J1594 [477]. The quasi-steady response was assembled using two time-averaged solutions of constant, fully immersed yawed flow, at angles of $0^{\circ}$ and $36^{\circ}$. Figures 12 and $\underline{13}$ show time-averaged isosurfaces of the total pressure coefficient with values less than or equal to zero for these two cases. This parameter is useful in extracting the flow structures over the vehicle and show the flow's high yaw angle over the complete vehicle and large separation on the leeward side when fully immersed. This also gives a good indication of a strong vortex forming as flow rounds the leeward A-pillar but also a lack of this structure on the windward side which has been identified in the work using the Windsor body geometry by Favre [39]. For angles in between, a linear relationship between yaw angle and all aerodynamic loads was assumed. Thus as the crosswind profile followed cosine functions within the mixing layers, the loads assumed this profile. All quasi-steady loads acted through the center of gravity of the vehicle.

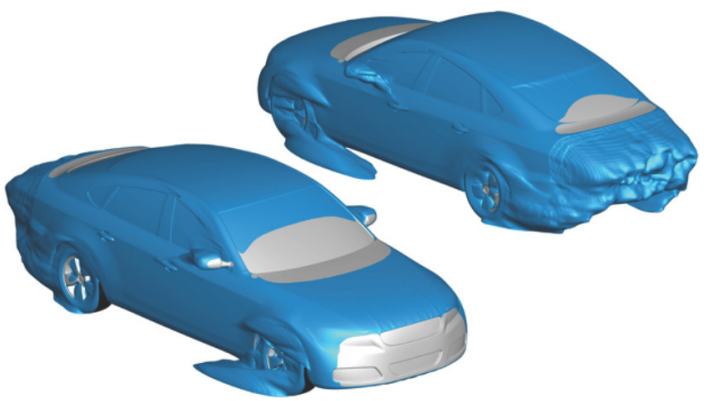

Figure 12. 0 Degree Yaw Angle, Time Averaged DES. Iso-surfaces of $c_{p t o t} \leq 0$.

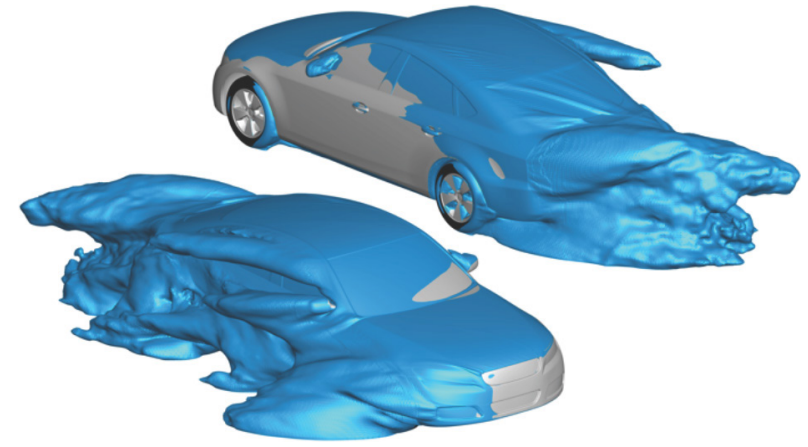

Figure 13. 36 Degree Yaw Angle, Time Averaged DES. Iso-surfaces of $c_{p t o t} \leq 0$.

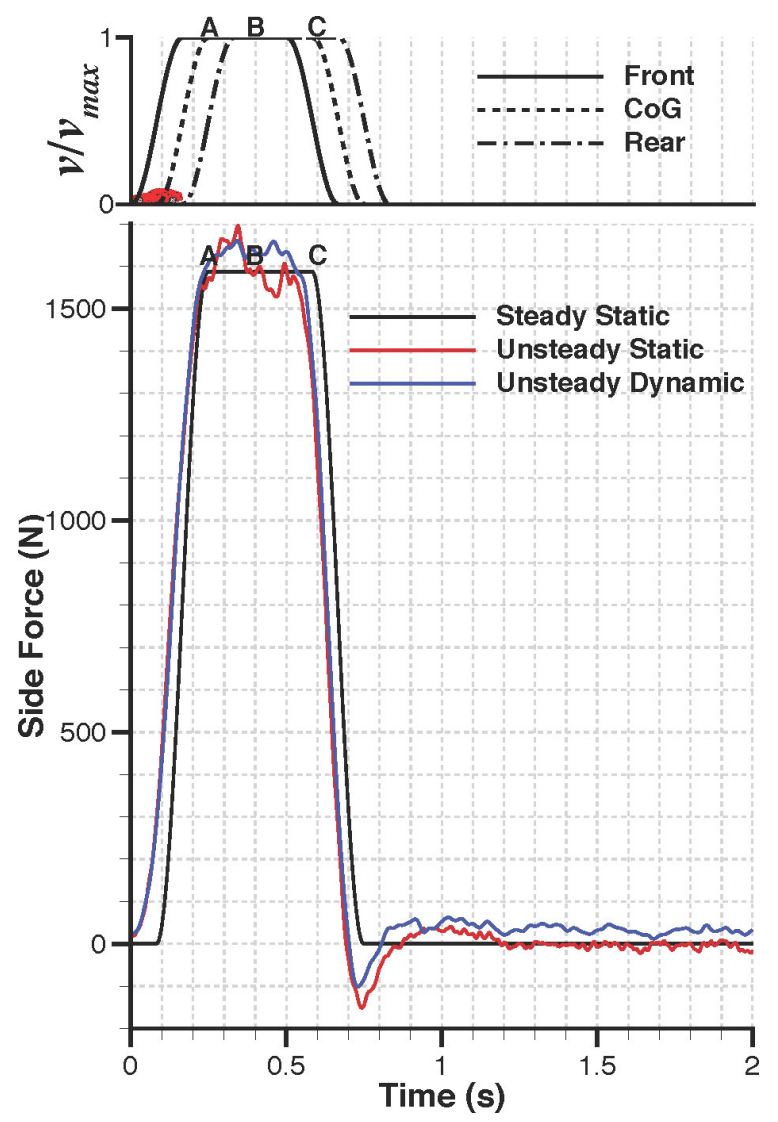

Figure 14. Aerodynamic Side Force. 
$\underline{\text { Figures } 14}$ and $\underline{15}$ show the aerodynamic side force and yawing moment respectively. In agreement with previous work, the quasisteady approach fails to capture the effects of entering and exiting the crosswind. These effects can be identified using a pressure difference variable where a negative pressure difference in the following figures indicates a lower pressure in the quasi-steady solution.

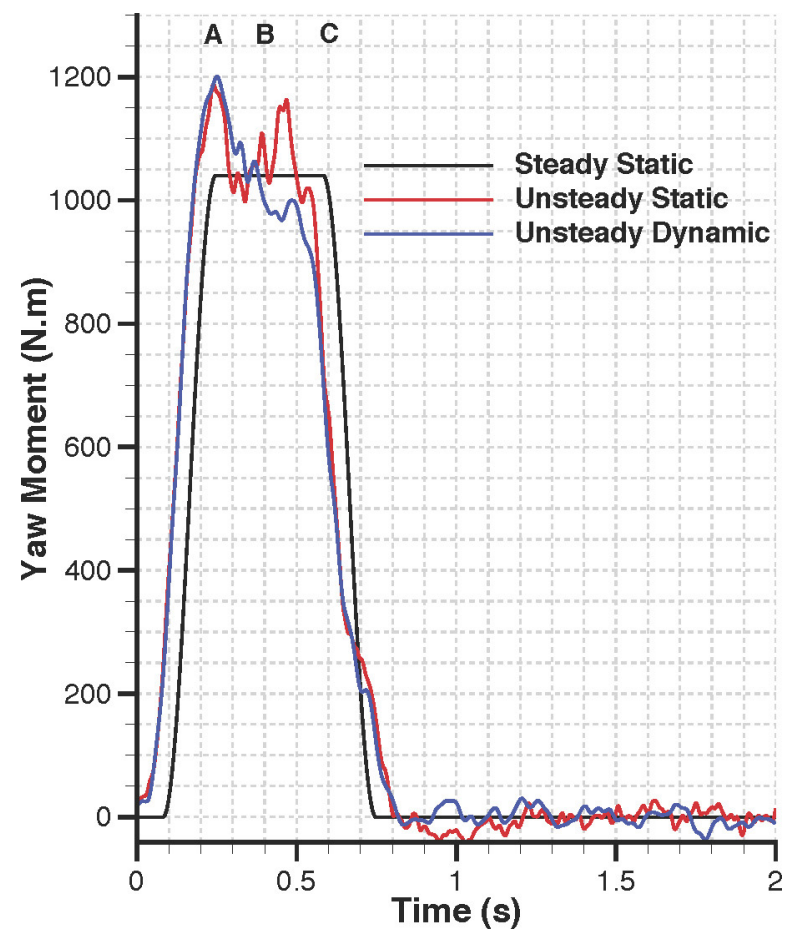

Figure 15. Aerodynamic Yaw Moment.
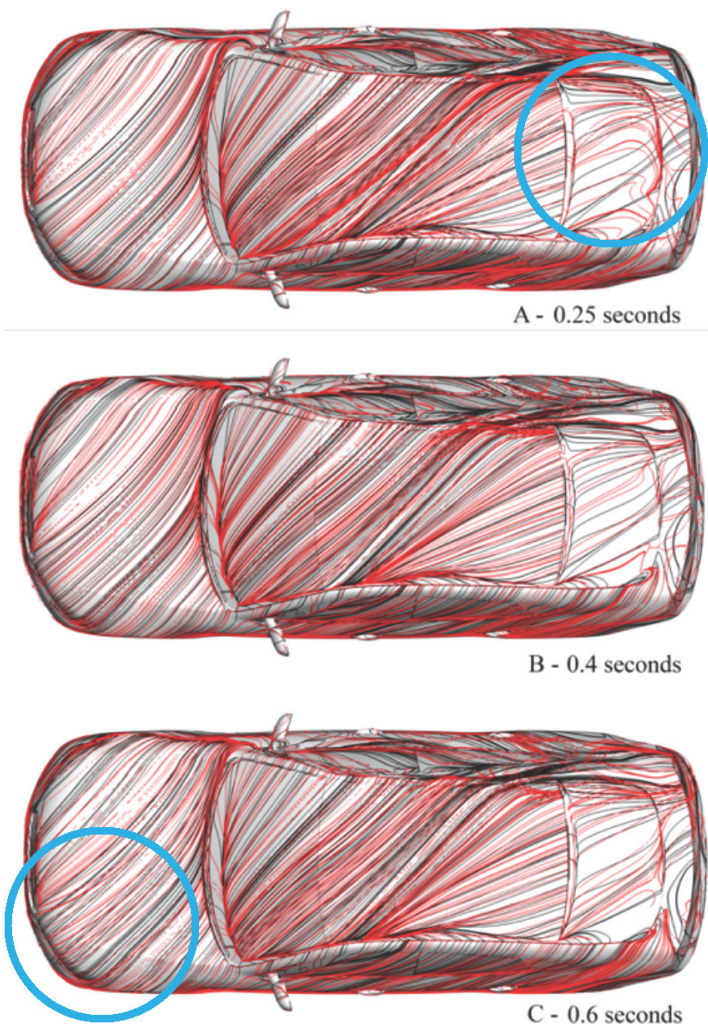

Figure 16. Surface Streamlines. Black $=$ Quasi-Steady Static, Red $=$ Unsteady Static.
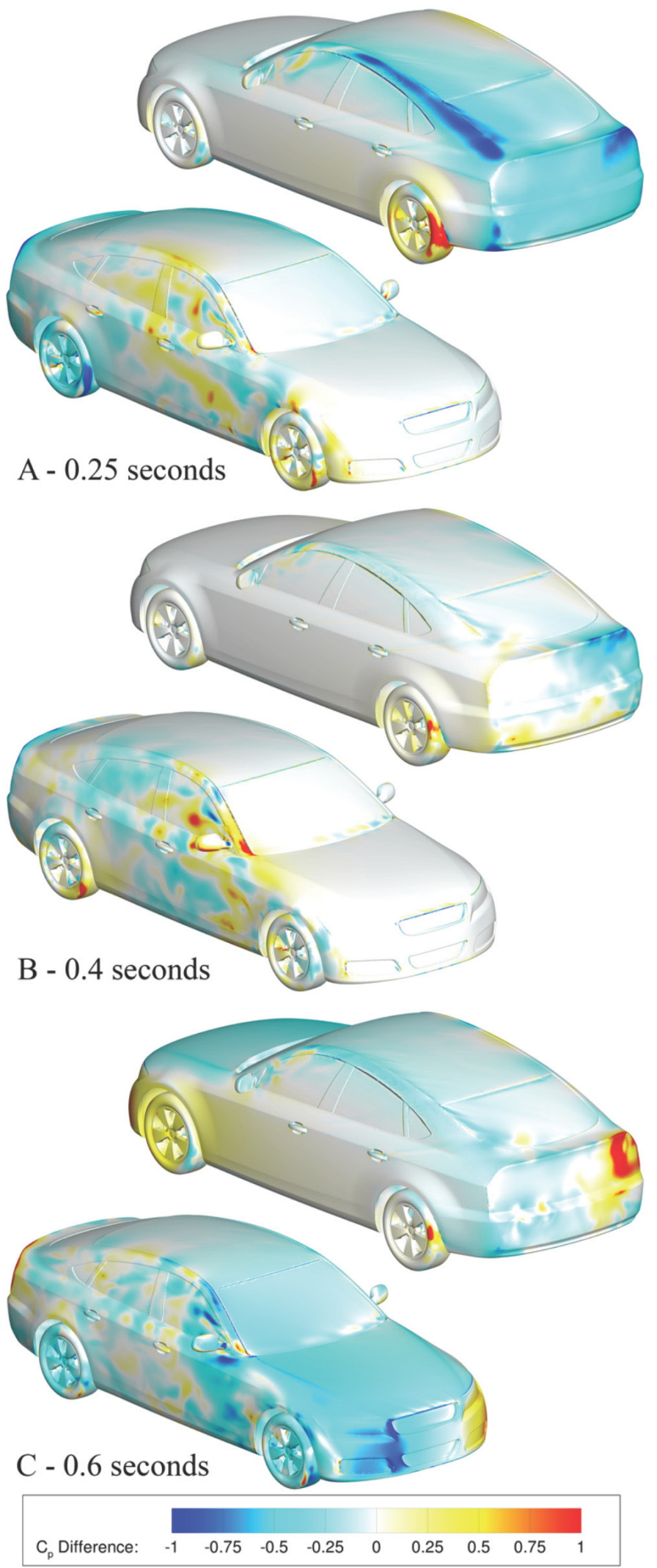

Figure 17. Pressure Difference [Steady Static - Unsteady Static] at 0.25 seconds. 
At point (A), 0.25 seconds after entering the crosswind, only the front half of the vehicle is exposed to the maximum yawed flow. This is shown by the surface streamlines in Figure 16 where the black and red lines indicate the quasi steady static and unsteady static solutions at this point respectively. Consequently, the flow rounding the windward rear $\mathrm{C}$ pillar is at much lower pressure in the fully immersed, quasi-steady case, Figure 17, where a negative pressure difference indicates a lower pressure in the steady-static case. This high velocity flow is responsible for the lower pressure on the backlight and boot-deck surfaces as well as the larger suction on the base. These in turn, lead to an over prediction in rear lift and pressure drag at this instant, Figures 18 and $\underline{19}$. The overshoot in yawing moment found in the unsteady cases at this point can be attributed to partial immersion of the vehicle in the crosswind, compared to the full immersion in the quasi-steady case. This can be seen by comparing the pressures over the rear of the vehicle between the unsteady-static and steady-static case, Figure 17, where a positive pressure difference indicates a higher pressure in the steady-static case.

Moving to a fully immersed vehicle at point (B - 0.4 seconds), the differences between the quasi-steady and unsteady solutions are minimal. Then as the vehicle exits the crosswind, point (C - 0.6 seconds), the front half of the vehicle is no longer exposed to the highly yawed flow, shown by the straightening of streamlines towards the front of the vehicle. Thus, the front stagnation moves towards the center of
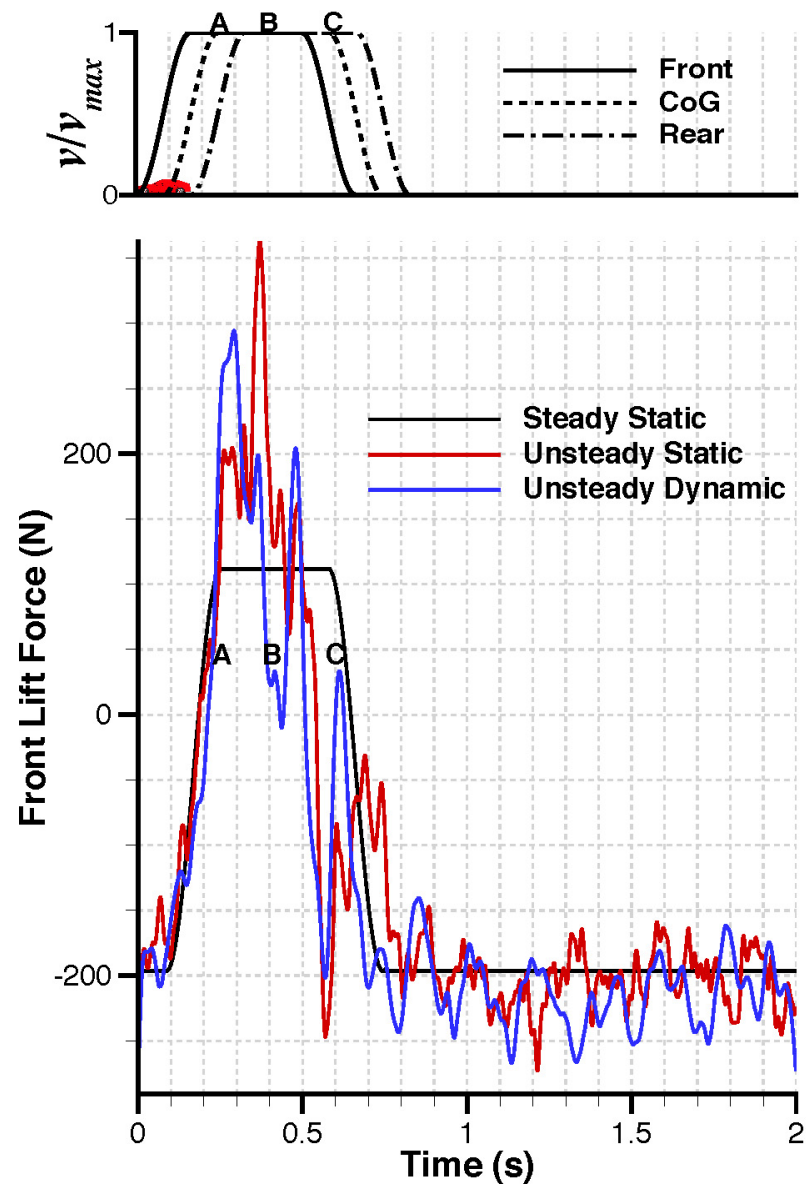

the bumper, causing a reduction in yawing moment. The quasi-steady case maintains the higher velocity flow over the bonnet responsible for the lower pressure on the surface and over prediction of front lift.

As expected and consistent with existing studies, the choice between a quasi-steady or unsteady approach has a significant impact on the flow field and resulting aerodynamics loads. However, the choice of coupling approach once an unsteady solver is selected appears to have a much smaller effect on the resulting aerodynamics. Both the unsteady static and unsteady dynamic aerodynamic side force, drag and yaw moment responses are very similar in their peak values, with the slight exception of the yaw moment response between B and C. During these points, the vehicle transitions from a fully to partially immersed state as it leaves the crosswind. In the unsteady dynamic response, the yaw moment decreases whereas, a second peak of similar magnitude to when entering the gust is predicted using the unsteady static method. Significant variations in the front and rear lift are predicted as the vehicle enters and exits the crosswind, in particular a large peak in rear lift using the unsteady static method as the front of the vehicle exits the crosswind. This is due to a region of higher pressure on the underbody surface and leeward rear wheel, as shown by the pressure delta in Figure 20. This is an indication of variations in the wakes of the fixed, non-rotating wheels. By including wheel rotation, these variations may subside as the flow around and through the wheel will be influenced by rotational effects.
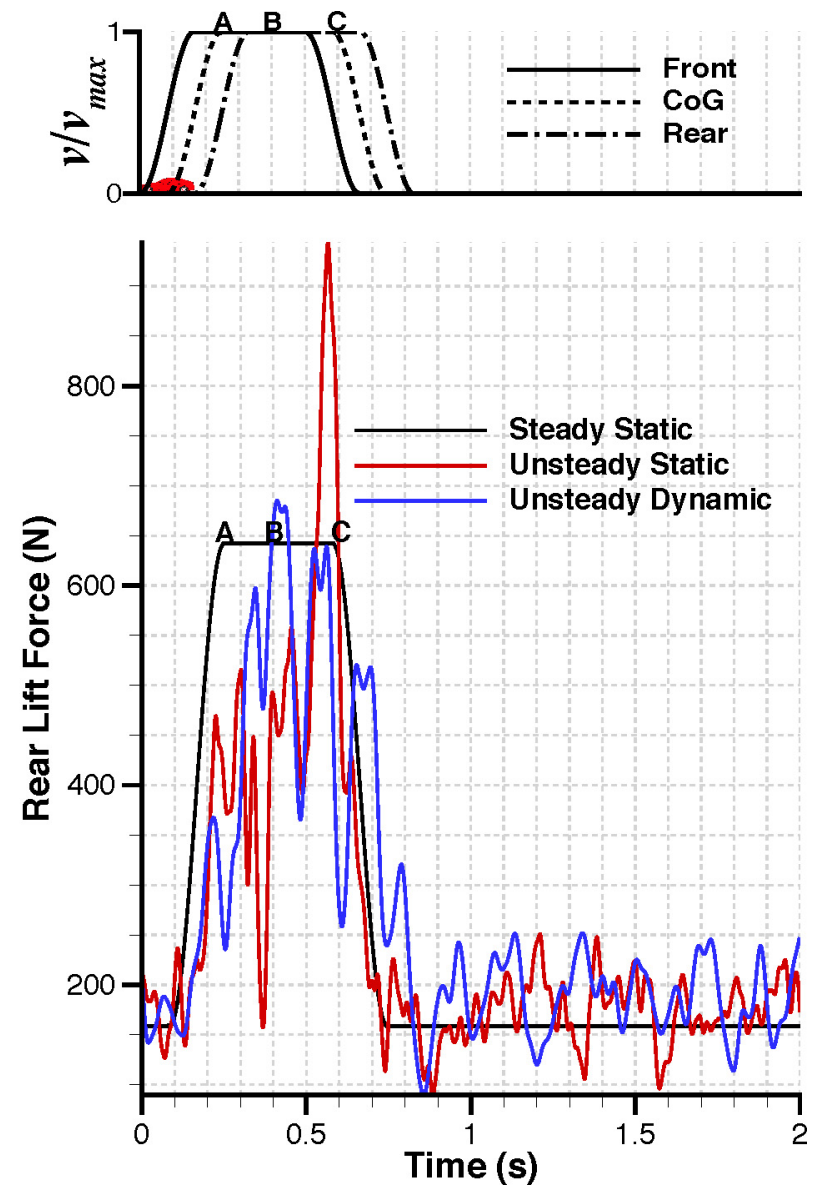

Figure 18. Aerodynamic Front and Rear Lift Force. 

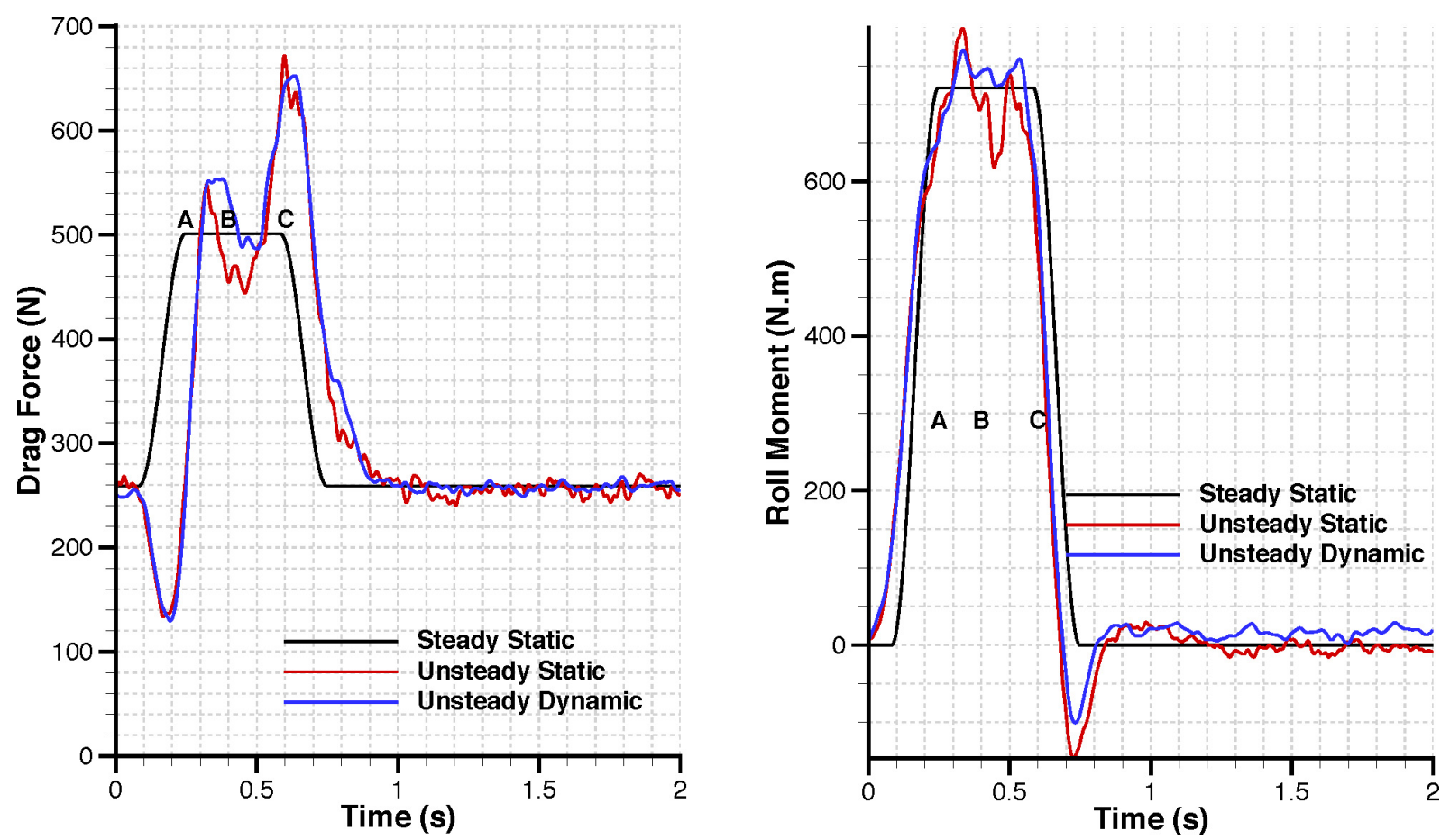

Figure 19. Aerodynamic Drag Force and Rolling Moment.

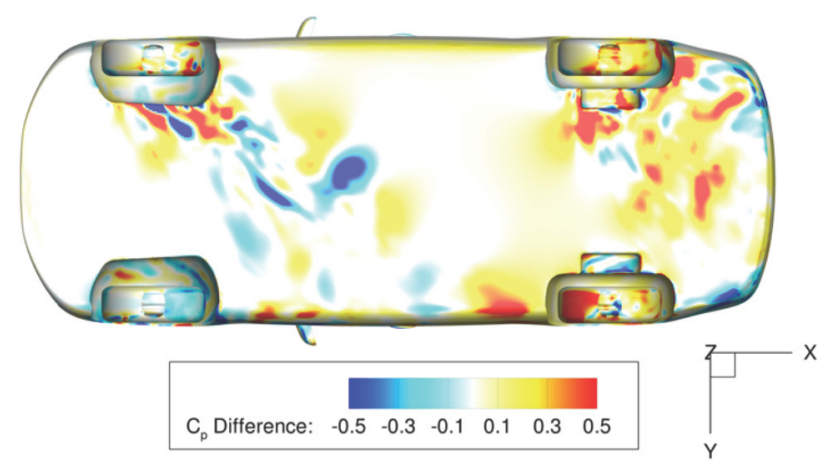

Figure 20. Pressure Difference [Unsteady Static - Unsteady Dynamic] at 0.55 seconds.

These loads in particular are heavily linked to vehicle stability and handling, thus comparisons of predicted vehicle response are needed in order to determine whether the variations in the aerodynamic loads have a proportional impact on handling.

\section{Vehicle Response}

The two most noticeable features of these responses are the delays between the unsteady and quasi-steady methods and the similarities of the unsteady methods. The first is due to the aerodynamic loads acting through the center of gravity. By definition of the method, the quasi-steady method cannot account for the transient effect of the gust profile passing over the length of the vehicle. Thus the interpolated responses follow the flow yaw angle as measured at the vehicle's center of gravity. This additional delay may promote a different driver response. The second feature in the responses is due to the high similarities in the aerodynamics loads between the unsteady methods.

For all cases, as the vehicle passes through the crosswind it yaws. This rotation is in a positive direction due to the reversal of the $\mathrm{z}$ axis in the vehicle dynamics coordinate system SAE J670 [48]. The motion is mainly due to the high pressure acting on the front left corner of the vehicle. As there is no driver response, the yaw angle continues to grow until the vehicle emerges from the crosswind where, with a slight delay, it settles at a constant angled orientation to its initial position. This along with slip forces acting on the tyres is responsible for the large lateral deviation of $1.7 \mathrm{~m}$ for the steady and $1.85 \mathrm{~m}$ for the unsteady methods, after two seconds, Figure 21 . The magnitude of this deviation is similar to that obtained experimentally by Howell [11]. Although these tests were performed on a small SUV geometry with a longer crosswind duration $\sim 10$ car lengths and smaller maximum yaw angle 27.5 degrees, the vehicle reached an average lateral deviation of $2 \mathrm{~m}$.

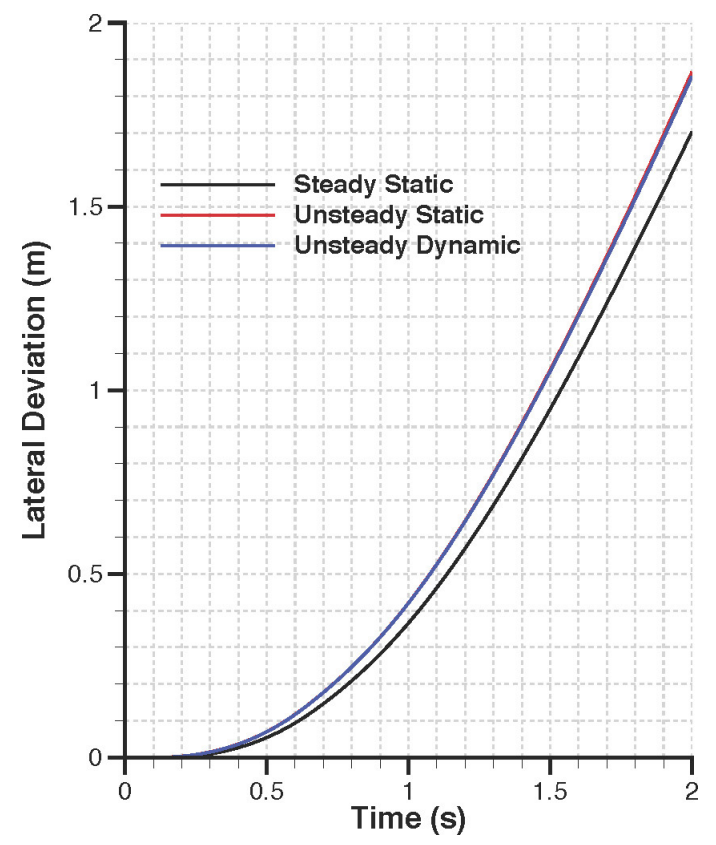

Figure 21. Vehicle Response: Lateral Deviation. 

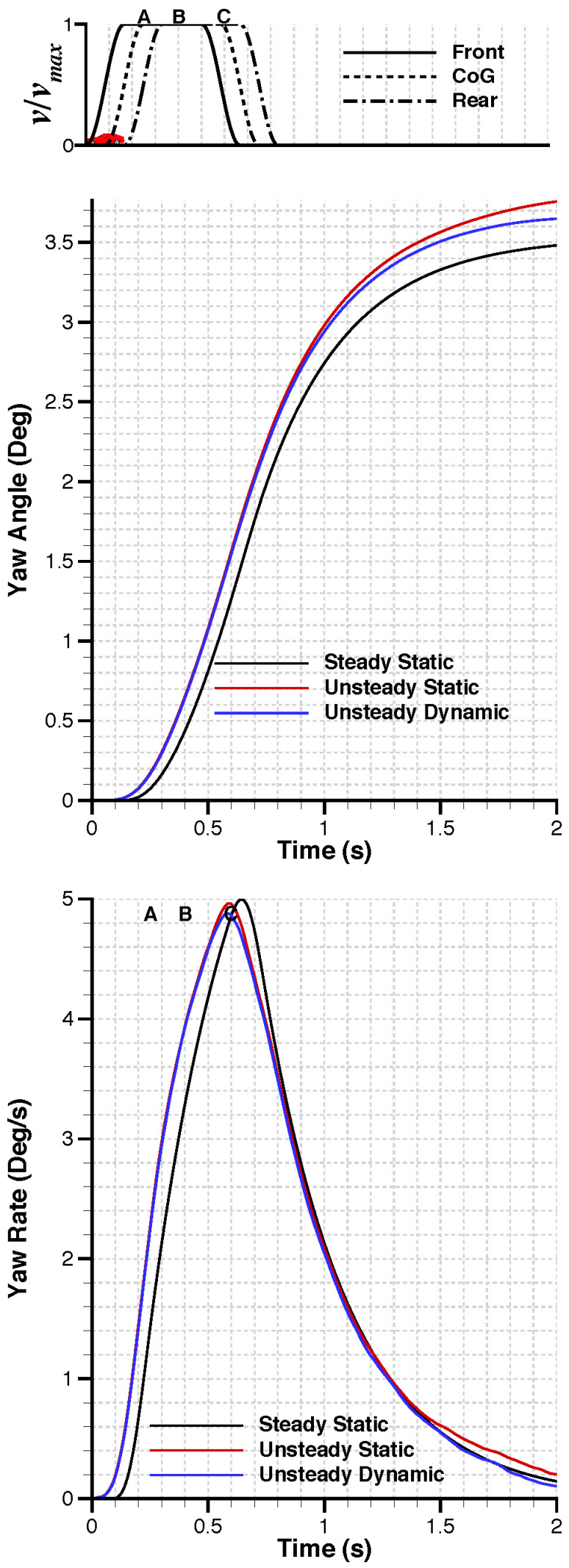
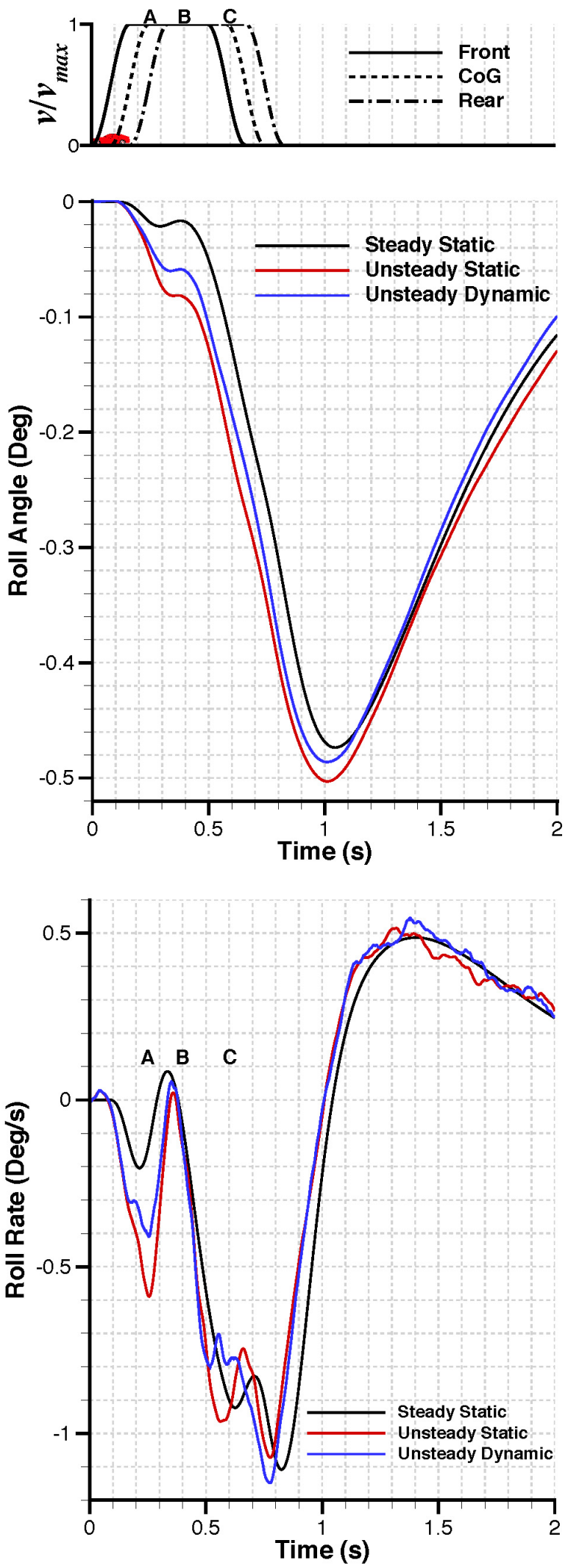

Figure 22. Vehicle Yaw and Rolling angles and rates.

The yaw angle values after two seconds vary based on the method employed, Figure 22. Analyzing the yaw rate of the vehicle, it is clear that the quasi-steady method predicts the smallest settled yaw angle of $3.50^{\circ}$ due to the initial delay in yaw rate. The largest settled yaw angle $3.78^{\circ}$, an increase of $8 \%$, reached by the unsteady-static approach, is due to a shallower gradient in the rate after exiting the crosswind between 1.5 and 2 seconds. The slight differences in the peak values between all approaches can be traced back to the variations in aerodynamic yaw moment during points (B) and (C). 
The roll angle and roll rate responses behave in a similar fashion to those of yaw, with a delay in the quasi-steady response and variations in the peak values reached. As the vehicle passes through the crosswind, it rolls towards the windward side, into the gust. An initial peak in roll rate at point (A) comes as a result of an overshoot in the aerodynamic roll moment. The rate becomes increasingly negative as the vehicle remains fully immersed.

The high similarities in the unsteady vehicle responses are most likely due to the differing timescales of the vehicle's motion and its aerodynamics, with the larger timescales of the vehicle's motion causing a delay in the response. More specifically, the large inertias of the vehicle, particularly yaw inertia, compared to the aerodynamic forces restrict any sizeable motion of the vehicle during the event. Hence, a longer gust duration, will allow the vehicle's orientation to grow further whilst immersed in the gust. In this case it is reasonable to expect differences between the coupling methods to emerge.

\section{CONCLUSIONS}

A fully coupled, 6 degrees of freedom system, in which a vehicle's aerodynamics and handling are simulated simultaneously through CFD and control systems software has been designed. The applicability and necessity of the system has been assessed by comparing to simplified one-way coupled methods in the simulation of a severe crosswind event.

In terms of aerodynamics, the positional accuracy of the vehicle throughout the event appeared to have very little influence. The overriding result was the requirement for an unsteady CFD solver in order to capture accurately the effects of the vehicle entering and exiting the crosswind. In particular, these were an overshoot in the yawing moment as well as over and under predictions in the front and rear lift.

Despite the fact that these quantities are heavily linked to a vehicle's handling and stability, the large variations in the aerodynamic loads were not reflected in the vehicle's dynamic response. Between the unsteady and quasi-steady methods there was a difference in lateral course deviation of $9 \%$ and yaw angle of $11 \%$ after two seconds without driver input, however this was mainly due to a delayed input of the quasi-steady loads acting through the centre of gravity. This time lag may have an impact on a driver's response and this is to be investigated.

Between the one-way and fully coupled unsteady approaches, variations in these parameters were minimal and hence the unsteady static method is sufficient for this particular event. It was felt that the large inertias of the vehicle, particularly yaw inertia, compared to the aerodynamic forces restricted any sizeable motion of the vehicle during the event. A crosswind event with longer duration, may promote more noticeable variations and hence is the next application of this simulation method.

\section{REFERENCES}

1. Howell, J., "Real Environment for Vehicles on the Road," presented at Euromotor - Progress in Vehicle Aerodynamics, Stuttgart, 2000.

2. Engineering Sciences Data Unit, "Strong winds in the atmospheric boundary layer Part 1: hourly-mean wind speeds," ESDU 82026, 2002, ISBN: 9780856794070
3. United Nations Economic Commission for Europe (UNECE), "Proposal for a new global technical regulation on the Worldwide harmonized Light Vehicles Test Procedure (WLTP)," ECE/TRANS/WP.29/2014/27, 2014,

4. Wagner, A. and Wiedemann, J., "Crosswind Behavior in the Driver's Perspective," SAE Technical Paper 2002-01-0086, 2002, doi:10.4271/2002-01-0086.

5. Saunders, J. and Mansour, R., "On-Road and Wind Tunnel Turbulence and its Measurement Using a Four-Hole Dynamic Probe Ahead of Several Cars," SAE Technical Paper 2000-01-0350, 2000, doi: $10.4271 / 2000-01-0350$.

6. Wordley, S. and Saunders, J., "On-road Turbulence," SAE Int. J. Passeng. Cars - Mech. Syst. 1(1):341-360, 2009, doi:10.4271/2008-01-0475.

7. Wordley, S. and Saunders, J., "On-road Turbulence: Part 2," SAE Int. J. Passeng. Cars - Mech. Syst. 2(1):111-137, 2009, doi:10.4271/2009-01$\underline{0002 .}$.

8. Wojciak, J. et al., "Experimental Study of On-Road Aerodynamics during Crosswind Gusts," presented at 8th MIRA International Vehicle Aerodynamics Conference, Grove, UK, Oct 2010.

9. D'Hooge, A., Rebbeck, L., Palin, R., Murphy, Q. et al., "Application of Real-World Wind Conditions for Assessing Aerodynamic Drag for On-Road Range Prediction," SAE Technical Paper 2015-01-1551, 2015, doi:10.4271/2015-01-1551.

10. Klein, R. and Hogue, J., "Effects of Crosswinds on Vehicle Response - Full-Scale Tests and Analytical Predictions," SAE Technical Paper $\underline{800848}$, 1980, doi: $10.4271 / 800848$.

11. Howell, J., "Experimental Results from a Small SUV Tested in the MIRA Crosswind Generator," presented at MIRA International Vehicle Aerodynamics Conference, Birmingham, UK, 1996.

12. Applus IDIADA, "Crosswind Facility", http://www.applusidiada.com/ download/1340221810599-PG\%20-\%20Cross\%20Wind.pdf, accessed Sept 2015.

13. International Organization for Standardization, "Road Vehicles Sensitivity to lateral wind - Open-loop test method using wind generator input," ISO 12021:2010, Rev. 2010.

14. Beauvais, F., "Transient Nature of Wind Gust Effects on an Automobile," SAE Technical Paper 670608, 1967, doi: $\underline{10.4271 / 670608}$.

15. Bearman, P., and Mullarkey, S., "Aerodynamic Forces in Road Vehicles Due to Steady Side Winds and Gust," presented at Royal Aeronautical Society Vehicle Aerodynamics Conference, Loughborough, UK, 1994.

16. Passmore, M., Richardson, S., and Imam, A., "An experimental study of unsteady vehicle aerodynamics," Proceedings of the IMechE Part D Journal of Automobile Engineering 215, 779-788, Feb 2001.

17. Schroeck, D., Krantz, W., Widdecke, N., and Wiedemann, J., "Unsteady Aerodynamic Properties of a Vehicle Model and their Effect on Driver and Vehicle under Side Wind Conditions," SAE Int. J. Passeng. Cars Mech. Syst. 4(1):108-119, 2011, doi:10.4271/2011-01-0154.

18. Mankowski, O., Sims-Williams, D., and Dominy, R., "A Wind Tunnel Simulation Facility for On-Road Transients," SAE Int. J. Passeng. Cars Mech. Syst. 7(3):1087-1095, 2014, doi:10.4271/2014-01-0587.

19. Blumrich, R., Widdecke, N., Wiedemann, J., Michelbach, A. et al., "New FKFS Technology at the Full-Scale Aeroacoustic Wind Tunnel of University of Stuttgart," SAE Int. J. Passeng. Cars - Mech. Syst. 8(1):294-305, 2015, doi:10.4271/2015-01-1557.

20. Cogotti, A., "Generation of a Controlled Level of Turbulence in the Pininfarina Wind Tunnel for the Measurement of Unsteady Aerodynamics and Aeroacoustics," SAE Technical Paper 2003-01-0430, 2003, doi:10.4271/2003-01-0430.

21. Cogotti, A., "Update on the Pininfarina "Turbulence Generation System" and its effects on the Car Aerodynamics and Aeroacoustics," SAE Technical Paper 2004-01-0807, 2004, doi:10.4271/2004-01-0807.

22. Carlino, G., Cardano, D., and Cogotti, A., "A New Technique to Measure the Aerodynamic Response of Passenger Cars by a Continuous Flow Yawing," SAE Technical Paper 2007-01-0902, 2007, doi:10.4271/200701-0902.

23. Ryan, A. and Dominy, R., "The Aerodynamic Forces Induced on a Passenger Vehicle in Response to a Transient Cross-Wind Gust at a Relative Incidence of $30^{\circ}, "$ SAE Technical Paper 980392, 1998, doi:10.4271/980392.

24. Dominy, R. and Ryan, A., "An Improved Wind Tunnel Configuration for the Investigation of Aerodynamic Cross Wind Gust Response," SAE Technical Paper 1999-01-0808, 1999, doi:10.4271/1999-01-0808.

25. Ryan, A. and Dominy, R., "Wake Surveys Behind a Passenger Car Subjected to a Transient Cross-Wind Gust," SAE Technical Paper 200001-0874, 2000, doi:10.4271/2000-01-0874. 
26. Gaylard, A., Oettle, N., Duncan, B., and Gargoloff, J., "Effect of NonUniform Flow Conditions on Vehicle Aerodynamic Performance," presented at FKFS - 9th Aerodynamic Conference, Stuttgart, 2013.

27. D'Hooge, A., Rebbeck, L., Palin, R., Murphy, Q. et al., "Application of Real-World Wind Conditions for Assessing Aerodynamic Drag for On-Road Range Prediction," SAE Technical Paper 2015-01-1551, 2015, doi:10.4271/2015-01-1551.

28. Theissen, P., "Unsteady Vehicle Aerodynamics in Gusty Crosswind," Ph.D thesis, Technische Universität München, 2012.

29. Tsubokura, M., Nakashima, T., Ikenaga, T., Onishi, K. et al., "HPC-LES for the Prediction of Unsteady Aerodynamic Forces on a Vehicle in a Gusty Cross-flow Condition," SAE Technical Paper 2008-01-3001, 2008, doi:10.4271/2008-01-3001.

30. Tsubokura, M., Takahashi, K., Matsuuki, T., Nakashima, T. et al., "HPCLES for Unsteady Aerodynamics of a Heavy Duty Truck in Wind Gust - 1st report: Validation and Unsteady Flow Structures," SAE Technical Paper 2010-01-1010, 2010, doi: 10.4271/2010-01-1010.

31. Nakashima, T., Tsubokura, M., Ikenaga, T., and Doi, Y., "HPCLES for Unsteady Aerodynamics of a Heavy Duty Truck in Wind Gust - 2nd report: Coupled Analysis with Vehicle Motion," SAE Technical Paper 2010-01-1021, 2010, doi: 10.4271/2010-01-1021.

32. Tsubokura, M. et al., "Large eddy simulation on the unsteady aerodynamic response of a road vehicle in transient crosswinds," International Journal of Heat and Fluid Flow 31(6):1075-1086, Dec 2010.

33. Tsubokura, M., and Nakashima, T., "Unsteady Aerodynamic Simulator for Road Vehicles Based on Large-Eddy Simulation," presented at 8th MIRA International Vehicle Aerodynamics Conference, Grove, UK, Oct 2010.

34. Nakashima, T., Tsubokura, M., Matsuda, S., and Doi, Y., "Coupled Analysis of Unsteady Aerodynamics and 6DOF Motion of a Heavy Duty Truck in Strong Wind Gusts," presented at 29th AIAA Applied Aerodynamics Conference, Honolulu, Hawaii, 2011.

35. Nakashima, T. et al., "Coupled analysis of unsteady aerodynamics and vehicle motion of a road vehicle in windy condition," Computers and Fluids 80(10):1-9, July 2013.

36. Hucho, W. and Emmelmann, H., "Theoretical Prediction of the Aerodynamic Derivatives of a Vehicle in Cross Wind Gusts," SAE Technical Paper 730232, 1973, doi: 10.4271/730232.

37. Heft, A., Indinger, T., and Adams, N., "Introduction of a New Realistic Generic Car Model for Aerodynamic Investigations," SAE Technical Paper 2012-01-0168, 2012, doi:10.4271/2012-01-0168.

38. Theissen, P., "Unsteady Vehicle Aerodynamics in Gusty Crosswind," Ph.D thesis, Tehnische Universität München, Germany, 2012.

39. Favre, T., "Aerodynamics simulations of ground vehicles in unsteady crosswind," Ph.D thesis, KTH School of Engineering Sciences, Stockholm, Sweden, 2011.

40. Wojciak, J. et al., "Experimental Study of On-Road Aerodynamics during Crosswind Gusts," presented at 8th MIRA International Vehicle Aerodynamics Conference, Grove, UK, Oct 2010

41. Demuth, R., and Buck, P., "Numerical Investigations on the Unsteady Aerodynamics of Road Vehicles Under Gusty Weather Conditions," presented at 6th MIRA International Vehicle Aerodynamics Conference, Gaydon, UK, Oct 2006.
42. Wieser, D., Schmidt, H., Müller, S., Strangfeld, C. et al., "Experimental Comparison of the Aerodynamic Behavior of Fastback and Notchback DrivAer Models," SAE Int. J. Passeng. Cars - Mech. Syst. 7(2):682-691, 2014, doi:10.4271/2014-01-0613.

43. Spalart, P., Deck, S., Shur, M., and Squires, K, "A new version of detached-eddy simulation, resistant to ambiguous grid densities," Theor. Comput. Fluid Dyn. 20:181-195, 2006, doi:10.1007/s00162-006-0015-0.

44. Forbes, D et al., "Computational study of wake structure and base pressure on a generic SUV model," presented at The International Vehicle Aerodynamics Conference, Loughborough, UK, Oct 2014, doi: $10.1533 / 9780081002452.2 .67$.

45. Ashton, N. and Revell, A., "Comparison of RANS and DES Methods for the DrivAer Automotive Body," SAE Technical Paper 2015-01-1538, 2015, doi:10.4271/2015-01-1538.

46. Best, M., "A Simple Realistic Driver Model," presented at 11th International Symposium on Advanced Vehicle Control (AVEC'12), Seoul, Korea, Sept 2012.

47. SAE Surface Vehicle Recommended Practice, "Vehicle Aerodynamics Terminology," SAE Standard J1594, Rev. Jul. 2010.

48. SAE Surface Vehicle Recommended Practice, "Vehicle Dynamics

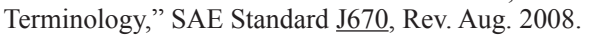

\section{CONTACT INFORMATION}

David Forbes

Aeronautical and Automotive Engineering Department

Stewart Miller Building

Loughborough University

Loughborough, UK

d.c.forbes@1boro.ac.uk

\section{ACKNOWLEDGMENTS}

The authors would like to acknowledge Jeff Howell for his valued contribution and support in this work.

In addition, the authors would like to thank Matt Best for his assistance with the handling model implementation and HPCMidlands who facilitated the CFD simulations.

This work was supported by Jaguar Land Rover and the UK - EPSRC grant EP/K014102/1 as part of the jointly funded Programme for Simulation Innovation.

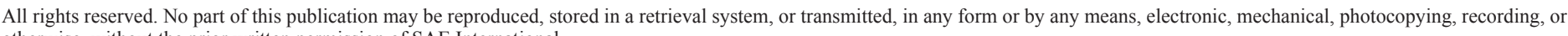
otherwise, without the prior written permission of SAE International. 